\title{
Visual Function And Quality Of Life In A Cohort Of Swedish Children With Juvenile Idiopathic Arthritis
}

This article was published in the following Dove Press journal: Clinical Ophthalmology

\author{
Rezhna Taha id \\ Maria Papadopoulou ${ }^{\mathrm{I} 2}$ \\ Madeleine Zetterberg ${ }^{1,2}$ \\ Solveig Oskarsdottir ${ }^{3}$ \\ Marita Andersson \\ Grönlund ${ }^{1,2}$ \\ 'Department of Clinical Neuroscience, \\ Institute of Neuroscience and Physiology, \\ Sahlgrenska Academy at the University of \\ Gothenburg, Gothenburg, Sweden; \\ ${ }^{2}$ Department of Ophthalmology, \\ Sahlgrenska University Hospital, Mölndal, \\ Sweden; ${ }^{3}$ Department of Pediatrics, \\ Institute of Clinical Sciences, Sahlgrenska \\ Academy at the University of \\ Gothenburg, Gothenburg, Sweden
}

Purpose: To evaluate quality of life (QoL) in children with juvenile idiopathic arthritis (JIA).

Methods: Forty children with a mean age of 7.9 years were included. The children underwent an ophthalmological examination and completed questionnaires on physical function (CHAQ) and vision-related (VR) QoL (EYE-Q).

Results: No differences regarding visual acuity (VA), refraction, intraocular pressure or physical or VRQoL were found between those with JIA without $(n=33)$ and those with JIAassociated uveitis $(n=7)$. When comparing physical function measured by CHAQ disability index and JIA subtype, a difference was found; children with polyarthritis scored the worst $(p=0.0098)$. Children with subnormal VA scored worse on EYE-Q compared with those with normal VA $(\mathrm{p}=0.013)$. We found correlations between duration of JIA and CHAQ disability index $(\mathrm{r}=-0.42, \mathrm{p}=0.0007)$ and CHAQ well-being $(\mathrm{r}=-0.34, \mathrm{p}=0.022)$.

Conclusion: This study indicates the importance of measuring not only physical function but also VRQoL in children with JIA and JIA-associated uveitis.

Keywords: child arthritis, juvenile idiopathic arthritis, PROM, uveitis, quality of life

\section{Introduction}

Juvenile idiopathic arthritis (JIA) consists of several subtypes of chronic arthritis with its onset of diagnosis before 16 years of age, and is defined as swelling or limitation of motion of the joints accompanied by heat, pain or tenderness of at least six weeks duration with no other identifiable causes of arthritis. ${ }^{1}$ Juvenile idiopathic arthritis is the most common chronic rheumatic disease in children in the Western world, and it may be a significant cause of chronic pain, disability and reduced quality of life (QoL). ${ }^{2,3}$

The incidence and prevalence in European and North American populations range from 2 to 20 and from 16 to 150 per 100,000, respectively. ${ }^{4}$ The International League of Associations for Rheumatology (ILAR) has provided classification of JIA consisting of seven subtypes, including systemic arthritis, oligoarthritis (OA) extended and persistent, polyarthritis (PA), rheumatoid factor (RF) positive and RF negative, enthesitis-related arthritis, psoriatic arthritis and undifferentiated arthritis or "other" JIA."

Vision-threatening uveitis is the most common extra-articular manifestation of JIA, with a cumulative incidence of approximately $9-21 \%$ in these patients. ${ }^{7-10}$
Correspondence: Rezhna Taha Department of Clinical Neuroscience, Institute of Neuroscience and Physiology, Sahlgrenska Academy at the University of Gothenburg, Gothenburg, Sweden

Tel +46 3I 704093555

Fax +4631848952

Email rezhna.taha.najim@vgregion.se 
JIA-associated uveitis (JIA-U) may develop before, at the same time as, or after the arthritis onset and is often asymptomatic at the time of onset. JIA-U can lead to severe visual impairment and is a relevant cause of ocular morbidity in children. ${ }^{11,12}$ The JIA-U is typically anterior and chronic, and frequently affects both eyes. Serious ocular complications can occur (e.g. cataract, glaucoma, band keratopathy and posterior synechiae), probably causing visual impairment in affected children. ${ }^{13}$ Risk factors for developing uveitis include antinuclear antibody (ANA) positivity, early onset of JIA, JIA duration, certain human leukocyte antigen (HLA) markers and active disease state and elevated erythrocyte sedimentation rate (ESR). ${ }^{8-10,13-15}$

Our primary objective was to evaluate and compare visual and physical function and vision-related (VR)QoL in children with JIA and JIA-U who were screened and/or treated for uveitis at the Department of Pediatric Ophthalmology at the Queen Silvia Children's Hospital in Gothenburg, Sweden.

\section{Materials And Methods}

A prospective cohort study was performed on 40 Caucasian children (31 girls, 9 boys) with a mean age of 7.9 years (range 3.1-11.8 years), diagnosed with JIA according to ILAR criteria. Patients having JIA with ongoing uveitis or children followed up for previous uveitis as well as JIA children screening for uveitis during 2013-2014 were included. All children underwent a detailed ophthalmological examination (by one of the authors, MP) including best corrected visual acuity (BCVA), refraction, intraocular pressure (IOP), slit-lamp inspection, ophthalmoscopy of the fundus and optic coherence tomography (OCT). We also registered any current and/or previous ocular complications secondary to uveitis, previous eye surgery and age at onset of uveitis. Ocular inflammation was defined according to the Standardization of Uveitis localisation of the inflammation. The classification includes 1) location of uveitis, 2) onset, duration and course of uveitis and 3 ) severity and activity of uveitis. ${ }^{16}$

\section{Ophthalmological Examination}

VA was tested with a linear KM-Boks chart. ${ }^{17}$ If a child could not manage to read the KM-Boks chart, an HOTV chart was used. Distance VA was tested monocularly and binocularly at a distance of $3 \mathrm{~m}$. Values were noted in decimal and transformed to $\log$ MAR units. Visual acuity of children with JIA was compared with an age- and sex-matched control group consisting of 55 healthy children (13 boys, 42 girls) with a mean age of 7.9 years (range 4.1-12.1 years). Refraction was performed with an autorefractor (Topcon A6300; Topcon Corporation, Tokyo, Japan), undilated as well as dilated after a single instillation of a mixture of cyclopentolate $(0.85 \%)$ and phenylephrine $(1.5 \%)$. Refractive errors were defined as the spherical equivalent (SE) of myopia $\geq 0.5$ dioptres (D), hyperopia $\geq 2.0 \mathrm{D}$ or anisometropia $\geq 1.0 \mathrm{D}$. Astigmatism was considered significant at a level of $\geq 1.0 \mathrm{D}$.

IOP was measured by a handheld tonometer (TA0li, I care, Finland Oy, Espoo, Finland). Readings with high deviations were discarded and repeated. Findings such as band keratopathy, flare and cells, posterior synechiae, cataract, vitritis, and macular and/or papilledema were especially noted. The morphology of the fundus was further examined using an OCT (3D OCT-2000, Topcon, Corporation, Japan, 2012), e.g. for detection of macular edema.

\section{Paediatric Data}

The following variables were collected and documented from medical records: gender, age, ethnicity, arthritis subtype, age at onset and duration of arthritis and presence of ANA. All topical and systemic anti-inflammatory and immunosuppressive medications were recorded.

\section{Questionnaires On Quality Of Life Visual Function Assessment And Vision-Related Quality Of Life}

Visual function and VRQoL were measured by the Effects of Youngsters' Eyesight on Quality of Life instrument (EYE-Q). The EYE-Q instrument consists of 13 selfreported items for individuals $\geq 8$ years of age that evaluate competence in performing daily tasks that rely on vision in the school and at home. ${ }^{2,18}$ It requires 10 mins to complete. Those children younger than 8 years old completed the questionnaire together with the parents. This questionnaire uses a 5-point Likert scale in 12 of the items (items which asses the difficulties to see the colors on a stoplight, the words in the school book, the food on the plate, etc.). The following response format is used to assess difficulty in performing tasks, with response options as follows: 1 (not hard/never); 2 (a little hard/rarely); 3 (hard/sometimes); 4 (very hard/often) and 5 (cannot do). The items were rescaled, with the scores ranging from 0 to $4^{2}$ higher scores indicated worse QoL. ${ }^{2,18-20}$ The 13th item, which is about whether there are other things that are difficult to do related to the child's vision, uses yes or no alternatives. 


\section{Physical Function Assessment}

Physical function was measured by the Child Health Assessment Questionnaire (CHAQ), which is a diseasespecific instrument for JIA and a valid measurement of functional disability. ${ }^{18,21}$ It is adapted from the Stanford Health Assessment Questionnaire and has well-documented reliability and validity. ${ }^{2,22}$ We evaluated two parallel questionnaires, one for parents $(n=25)$ and another for children older than 8 years of age $(n=15)$.

It consists of a "disability index" of 30 questions within eight functional components: 1) dressing and grooming, 2) arising, 3) eating, 4) walking, 5) hygiene, 6) reach, 7) grip and (8) activities. There are three components within each area: 1) difficulty in performing daily functions, 2) use of special aids or devices and 3) activities that require assistance from another person. Each question has a 4-point response scale $(0=$ no difficulty; $1=$ some difficulty; $2=$ much difficulty; $3=$ unable to do). Scores range from 0 (no disability) to 3 (maximum disability), where higher scores indicate worse physical function. ${ }^{2,18,22}$

CHAQ also includes two other components: 1) "Assessment of discomfort", using a 10-cm visual analogue scale (VAS) for the evaluation of pain and its severity in the past week, whereby a score of 0 indicates "no pain" and 10 indicates "extreme pain"23 2) "Overall well-being" (global assessment), also using a 10-cm VAS, ranging from "very well" (score of 0 ) to "very bad" (score of 10). ${ }^{24}$

In the Swedish version of CHAQ, two other parts are also included, one consisting of information about whether the children have been absent from school due to arthritis during the last two months, and another component providing information about the children's participation in school gymnastics.

\section{Correlations}

Age at onset and duration of both JIA and uveitis as well as VA in the better eye were analysed to establish any correlation with the following variables: physical function (CHAQ disability index; CHAQ discomfort; CHAQ well-being) and visual function and VRQoL measured by EYE-Q.

\section{Statistical Analysis}

Percentages, means and standard deviations (SDs), median and ranges were calculated for descriptive purposes. For comparison between groups, Fisher's Exact test was used for dichotomous variables, and Mann-Whitney $U$-test and
Kruskal-Wallis test were used for continuous variables. Correlation analyses were performed using Pitman's partial-rank correlation analysis. Test results were considered significant if $\mathrm{p}<0.05$.

The healthy controls were selected individually by minimizing the maximal $t$-values between the group of JIA children at assessment and a reference group of healthy Swedish school-aged children ${ }^{25}$ over the variables age and sex. This method matches two populations by iteratively selecting the individuals with the minimum $t$-test score. ${ }^{26}$

\section{Ethical Approval}

The study was approved by the Research Ethics Board at the University of Gothenburg, Sweden. All candidates and their guardians received detailed information about the nature of the investigation, after which written informed consent was collected. All procedures were performed in accordance with the tenets of the Declaration of Helsinki.

\section{Results}

The clinical characteristics of the 40 children with JIA, divided into those with JIA-U $(n=7)$ or JIA alone $(n=33)$ are summarized in Table 1. The children with JIA were categorized by subtype, as defined by ILAR. Characteristics of the seven children (17.5\%), two boys and five girls, who had uveitis at assessment or have had uveitis in the past, are shown in Table 2. The mean age of arthritis onset in children with JIA-U was 3.3 years (range 1.5-5.3 years), and in children without uveitis it was 3.8 years (range 1.4-11.3 years). All children with JIA-U developed uveitis after being diagnosed with JIA. Several ocular complications were found such as bilateral band keratopathy, synechiae, cataract and ocular hypertension. Furthermore, ongoing inflammation (keratic precipitate, flare and cells) was noted in two cases at assessment.

Results of BCVA and refraction are shown in Table 3. There was no significant difference regarding IOP between the children with JIA alone (RE mean (SD) $14.9 \pm 3.7 \mathrm{~mm}$ $\mathrm{Hg}$; LE mean (SD) $15 \pm 3.2 \mathrm{~mm} \mathrm{Hg}$ ) and those with JIA$\mathrm{U}$ (RE mean (SD) $15.4 \pm 4.3 \mathrm{~mm} \mathrm{Hg}$; LE mean (SD) $14.6 \pm 2.6 \mathrm{~mm} \mathrm{Hg} ; \mathrm{p}=0.79, \mathrm{p}=0.77$, respectively). Performed OCT on the children showed normal imaging, i.e. no sign of macular edema could be detected.

The results from the questionnaires (CHAQ and EYE-Q) are summarized in Table 4. When comparing the three major components of CHAQ between the self-reports (children $\geq 8$ years, $\mathrm{n}=15$ ) and the parent reports (children $<8$ years, $n=25$ ), we could not find 
Table I Demographic Data On 40 Children With Juvenile Idiopathic Arthritis (IIA) Divided Into Those With JIA-Associated Uveitis $(n=7)$ Or Not $(n=33)$

\begin{tabular}{|c|c|c|c|}
\hline Demographics & $\begin{array}{l}\text { JIA children } \\
\mathrm{n}=40^{*}\end{array}$ & $\begin{array}{l}\text { Uveitis } \\
\mathrm{n}=7^{*}\end{array}$ & $\begin{array}{l}\text { No uveitis } \\
n=33^{*}\end{array}$ \\
\hline $\begin{array}{l}\text { Age at } \\
\text { assessment (yrs) } \\
\text { Mean (range) }\end{array}$ & $7.9(3.1-11.8)$ & $7.9(4.2-11.0)$ & $7.8(3.1-11.8)$ \\
\hline $\begin{array}{l}\text { Gender, n (\%) } \\
\text { - Male } \\
\text { - Female }\end{array}$ & $\begin{array}{l}9 \text { (22.5\%) } \\
31 \text { (77.5\%) }\end{array}$ & $\begin{array}{l}2(29 \%) \\
5 \text { (7।\%) }\end{array}$ & $\begin{array}{l}7(21 \%) \\
27(79 \%)\end{array}$ \\
\hline $\begin{array}{l}\text { Race, n (\%) } \\
\text { - Caucasian }\end{array}$ & $40(100 \%)$ & $7(100 \%)$ & $33(100 \%)$ \\
\hline $\begin{array}{l}\text { JIA disease } \\
\text { characteristics } \\
\text { - Age at JIA } \\
\text { diagnosis (yrs) } \\
\text { Mean (range) } \\
\text { - Duration of JIA } \\
\text { (yrs) Mean } \\
\text { (Range) }\end{array}$ & $\begin{array}{l}3.7(0.4-11.3) \\
4.2(0.7-9)\end{array}$ & $\begin{array}{l}3.3(1.5-5.3) \\
4.9(1.6-8.3)\end{array}$ & $\begin{array}{l}3.8(1.4-11.3) \\
4.1(0.7-9)\end{array}$ \\
\hline $\begin{array}{l}\text { JIA subtype, n (\%) } \\
\text { - Systemic } \\
\text { - Oligoarthritis } \\
\text { - } \text { persistent } \\
\text { - Oligoarthritis } \\
\text { extended } \\
\text { - Psoriatic } \\
\text { - Polyarthritis }\end{array}$ & $\begin{array}{l}\text { I (2.5\%) } \\
25(62.5 \%) \\
5(12.5 \%) \\
I(2.5 \%) \\
8(20 \%)\end{array}$ & $\begin{array}{l}0 \\
4(57 \%) \\
1(14 \%) \\
0 \\
2(29 \%)\end{array}$ & $\begin{array}{l}\text { I (3\%) } \\
2 \text { I (64\%) } \\
4(12 \%) \\
\text { I (3\%) } \\
6(18 \%)\end{array}$ \\
\hline $\begin{array}{l}\text { Labs, n (\%) } \\
\text { - } \text { ANA (+) } \\
\text { - } \text { RF }(-) \\
\text { - HLA B27 (+) }\end{array}$ & $\begin{array}{l}26(65 \%) \\
26(100 \%) \\
n=26 \\
3(100 \%) \\
n=3\end{array}$ & $\begin{array}{l}5(71 \%) \\
3(100 \%) \\
n=3 \\
0\end{array}$ & $\begin{array}{l}21(64 \%) \\
23(100 \%) \\
n=23 \\
3(100 \%) \\
n=3\end{array}$ \\
\hline
\end{tabular}

Notes: *Where numbers differ from the total number of children in the group, they are given separately for each category.

Abbreviations: ANA, antinuclear antibodies; HLA B27, human leukocyte antigen subtype B27; JIA, juvenile idiopathic arthritis; $n$, number of children; RF, rheumatic factor

any differences regarding CHAQ disability index and CHAQ discomfort. However, the parents reported higher CHAQ well-being scores, lower QoL than the children $(\mathrm{p}=0.012)$. When comparing physical function measured by CHAQ disability index and JIA subtype, a difference was found $(\mathrm{p}=0.0098)$, with children with PA $(n=8)$ having the highest score (0.46). We could not find any differences between JIA subtype and uveitis/no uveitis status.

All 40 children with JIA answered the 13th item of the EYE-Q. One of seven JIA-U children reported to have difficulty with photosensitivity. No children without uveitis reported any difficulty on the 13th item of EYE-Q.

Parents reporting any need of aids or devices for the children, and/or assistance of another person because of the disease, are shown in Figure 1A and B, divided into those with and without JIA-U. The self-reporting children did not report any need of aids and/or devices. Regarding children being home from school/pre-school due to their arthritis, the parents reported a total number of 10 children having a mean of 2.1 (range 1-4) days of absence in the past 2 months; three of these children had JIA-U. Thirtyfour of the 40 children with JIA went to school, and all of them participated in school gymnastics.

There were significant correlations between the duration of JIA and CHAQ disability index $(\mathrm{r}=-0.42$; $\mathrm{p}=0.0007)$ and CHAQ well-being $(\mathrm{r}=-0.34 ; \mathrm{p}=0.022)$. A correlation between BCVA LogMAR best eye and EYE-Q $(r=-0.36 ; p=0.042)$ was also found. When we compared JIA children with BCVA in the better eye $\leq 0.7$ decimal (0.2 LogMAR; $n=5)$ versus children with normal BCVA $(\mathrm{n}=35)$, we noticed that those with BCVA $\leq 0.7$ decimal had significantly worse EYE-Q scores $(p=0.013)$. However, this was not true for the three components of CHAQ regarding BCVA $\leq 0.7$ decimal versus normal BCVA (Table 5). Analysis at the individual level did not reveal any association between those with both JIA and uveitis and worse general QoL or worse EYE-O.

A total of 25 patients out of the 40 used some kind of disease-modifying antirheumatic drugs (DMARDs) and/or non-steroidal anti-inflammatory drugs, five with JIA-U and 20 without. Eleven of the 20 children with JIA alone and five children with JIA-U used DMARDs, either alone or in combination with both methotrexate and tumour necrosis factor (TNF)-alfa inhibitor. The TNFalpha drugs used in these cases were adalumimab ${ }^{\circledR}$ and etanercept ${ }^{\circledR}$. One child who had had JIA-U was not using any current medication, while another child with JIA-U had only used NSAID before the study enrolment (Figure 2A and B). One of the children with JIA-U was currently being treated with a combination of both Methotrexate ${ }^{\circledR}$ and Adalumimab ${ }^{\circledR}$ as well as local steroids (Dexamethasone ${ }^{\mathbb{R}}$ ) once a day, and antihypertensive eye drops (Betoptic $\mathrm{S}^{\mathbb{R}}$ ) twice a day. This patient had several ocular manifestations, such as cataract, ocular hypertension, posterior synechiae, vitritis and band keratopathy. None of our patients was on oral steroids. 


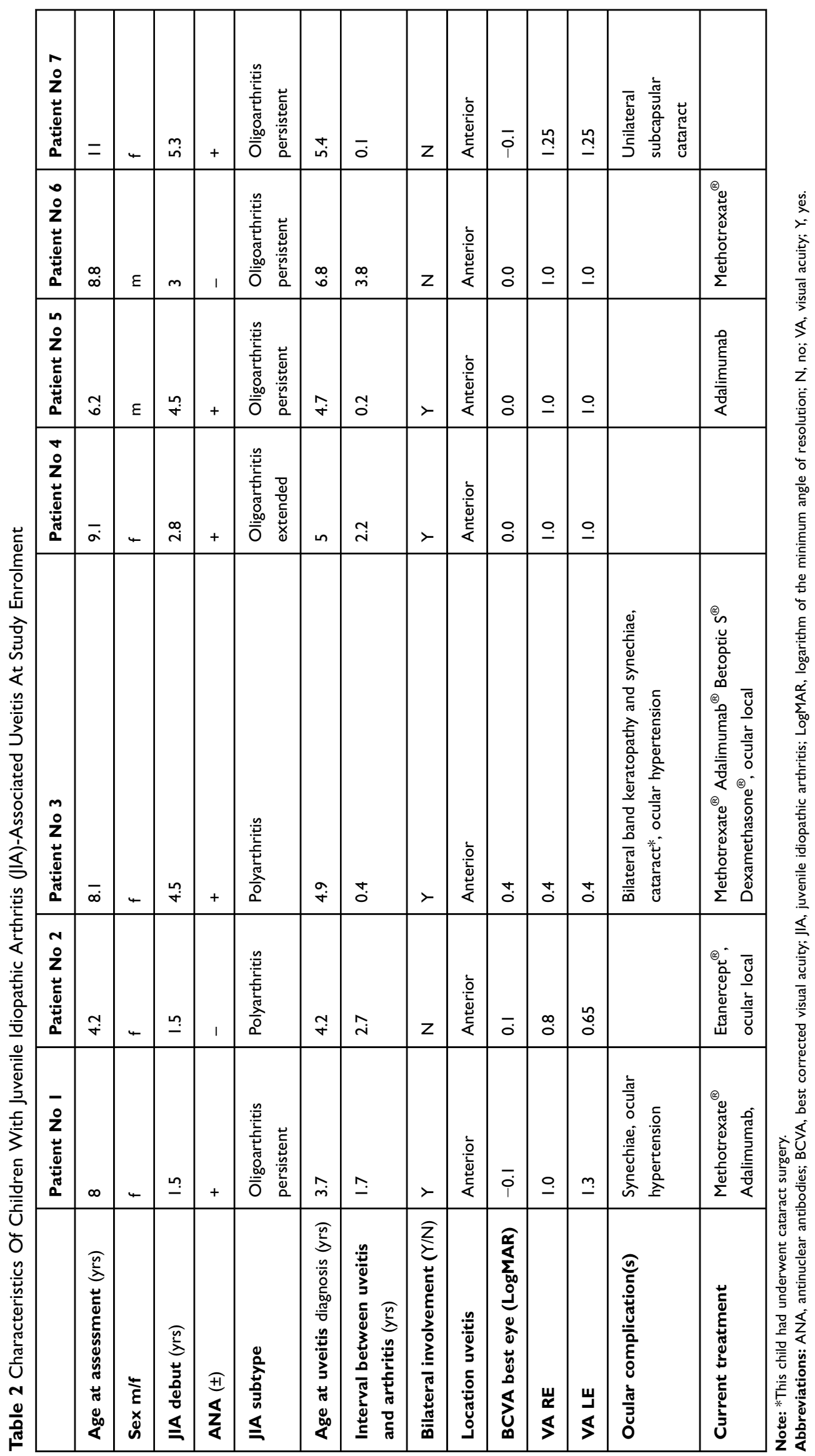




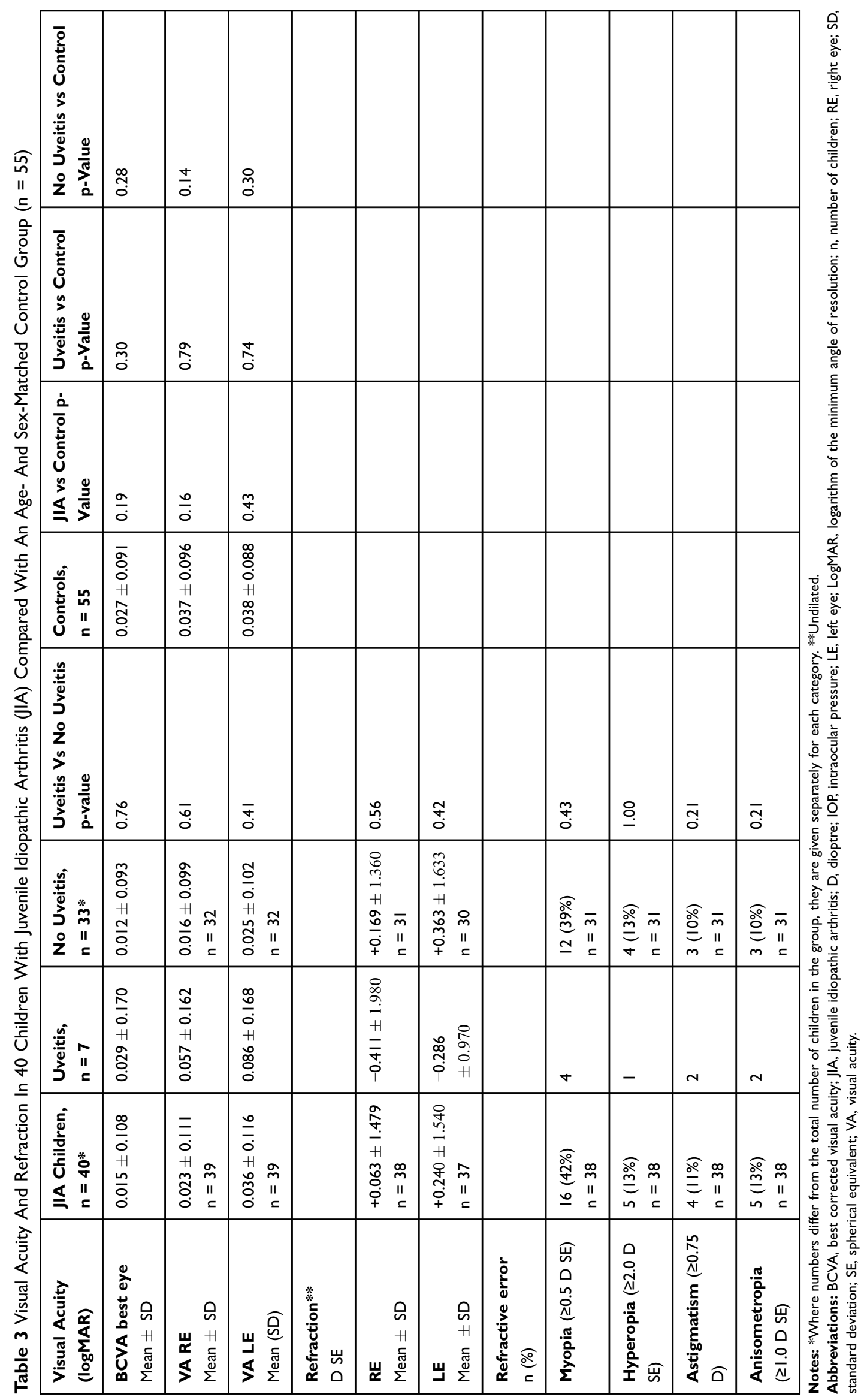


Table 4 Effects Of Youngsters' Eyesight On Quality Of Life Questionnaire (EYE-Q) And Child Health Assessment Questionnaire (CHAQ) Answered By Parents And Children at Assessment

\begin{tabular}{|c|c|c|c|c|}
\hline Questionnaires On QoL & $\begin{array}{l}\text { JIA Children, } \\
\mathrm{n}=40 *\end{array}$ & $\begin{array}{l}\text { Uveitis, } \\
\mathbf{n}=7^{*}\end{array}$ & $\begin{array}{l}\text { No Uveitis, } \\
\mathrm{n}=33^{*}\end{array}$ & P-Value \\
\hline $\begin{array}{l}\text { EYE-Q }(0-4)^{\mathrm{a}} \\
\text { Median outcome scores (range) }{ }^{* *}\end{array}$ & $0(0-0.56)$ & $0(0-0.08)$ & $0(0-0.56)$ & 0.78 \\
\hline $\begin{array}{l}\text { CHAQ }(0-3)^{\mathrm{a}} \text { disability index } \\
\text { Median outcome scores (range)** }\end{array}$ & $0(0-1.32)$ & $0(0-0.38)$ & $0(0-1.32)$ & 0.97 \\
\hline $\begin{array}{l}\text { CHAQ }(0-3)^{\mathrm{a}} \\
\text { self report } \geq 8 \mathrm{yrs}\end{array}$ & $\begin{array}{l}0(0-0.52) \\
\mathrm{n}=15\end{array}$ & $\begin{array}{l}0(0-0) \\
n=2\end{array}$ & $\begin{array}{l}0(0-0.52) \\
\mathrm{n}=13\end{array}$ & 0.44 \\
\hline $\begin{array}{l}\text { CHAQ }(0-3)^{\mathrm{a}} \\
\text { parent report }<8 y \text { rs }\end{array}$ & $\begin{array}{l}0.03(0-1.32) \\
n=25\end{array}$ & $\begin{array}{l}0.14(0-0.38) \\
n=5\end{array}$ & $\begin{array}{l}0.017(0-1.32) \\
\mathrm{n}=20\end{array}$ & 0.86 \\
\hline \multicolumn{5}{|l|}{ CHAQ VAS Median (range) } \\
\hline Pain $(0-10)^{a}$ & $0(0-4.7)$ & $0(0-3.5)$ & $0(0-4.7)$ & 0.58 \\
\hline $\begin{array}{l}\text { Pain }(0-10)^{\mathrm{a}} \\
\text { self report } \geq 8 \mathrm{yrs}\end{array}$ & $\begin{array}{l}0(0-4.2) \\
n=15\end{array}$ & $\begin{array}{l}0(0-0) \\
n=2\end{array}$ & $\begin{array}{l}0(0-4.2) \\
n=13\end{array}$ & 0.44 \\
\hline $\begin{array}{l}\text { Pain }(0-10)^{\mathrm{a}} \\
\text { parent report }<8 y \mathrm{rs}\end{array}$ & $\begin{array}{l}0.2(0-4.7) \\
n=25\end{array}$ & $\begin{array}{l}0(0-3.5) \\
n=5\end{array}$ & $\begin{array}{l}0.3(0-4.7) \\
n=20\end{array}$ & 0.83 \\
\hline Overall well-being $(0-10)^{\mathrm{a}}$ & $0.25(0-6.4)$ & $0(0-5.4)$ & $0.3(0-6.4)$ & 0.84 \\
\hline $\begin{array}{l}\text { Overall well-being }(0-10)^{\mathrm{a}} \\
\text { self report } \geq 8 \mathrm{yrs}\end{array}$ & $\begin{array}{l}0(0-2.5) \\
n=15\end{array}$ & $\begin{array}{l}0(0-0) \\
n=2\end{array}$ & $\begin{array}{l}0(0-2.5) \\
n=13\end{array}$ & 0.45 \\
\hline $\begin{array}{l}\text { Overall well-being }(0-10)^{\mathrm{a}} \\
\text { parent report }<8 y r s\end{array}$ & $\begin{array}{l}0.9(0-6.4) \\
n=25\end{array}$ & $\begin{array}{l}(0-5.4) \\
n=5\end{array}$ & $\begin{array}{l}0.75(0-6.4) \\
n=20\end{array}$ & 1.00 \\
\hline
\end{tabular}

Notes: *Where numbers differ from the total number of children in the group, they are given separately for each category. **Median (range) is calculated on the mean of the scores for CHAQ disability index - parent and self-reports. ${ }^{a}$ Higher scores indicate worse quality of life. Both pain and overall well-being were measured by a visual analog scale based on a Likert scale of $0-10 \mathrm{~cm}$, where higher score indicates more pain/worse well-being. CHAQ disability index scores range from 0 to 3 , at which 0 means without any difficulty and 3 means unable to do. We have excluded alternative 4 (not applicable) in our conclusion. EYE-Q scores range from 0 to 5 , at which 0 means no difficulty and 4 means unable to do. We have excluded alternative 5 (not applicable) in our conclusion. Higher scores for both CHAQ and EYE-Q indicate worse quality of life.

Abbreviations: CHAQ, Childhood Health Assessment Questionnaire; EYE-Q, Effects of Youngsters' Eyesight on Quality of Life Questionnaire; JIA, juvenile idiopathic arthritis; n, number of children; QoL, quality of life; VAS, visual analogue scale.

\section{Discussion}

JIA is the most common chronic rheumatic disease in childhood. Children with JIA may have long-term disability and affected QoL. Therefore, there has been an increasing need to assess the daily physical function as well as visual function status and VRQoL in patients with JIA and JIA-U. CHAQ is a valid, culturally adapted, reliable and sensitive tool for the evaluation of functional outcomes in children with chronic arthritis. $^{22,27}$ The aim of this study was to further evaluate visual and physical function and VRQoL in 40 children with JIA, of whom seven had JIA-U. We could not find any significant difference in QoL measured by CHAQ and EYE-Q between those with JIA alone and those with JIA-associated uveitis. However, this could be due to the fact that the patients were relatively stable in their JIA, but also due to the few cases with uveitis and/or other ocular problems. Furthermore, based on our results, the longer the duration of the arthritis disease, the more the overall QoL is affected.

Our results are consistent with previous studies showing that children with JIA are primarily Caucasian, female and have positive ANA. ${ }^{7,28}$ Having positive ANA is the most important predictor for developing uveitis. ${ }^{9}$ The mean age of arthritis onset in children who developed uveitis was 3.3 years and the mean time interval between diagnosis of arthritis and the diagnosis of uveitis was 1.6 years, which is in accordance with Heiligenhaus et $\mathrm{al}^{7}$ and Papadopoulou et al ${ }^{9}$ reporting 3.8 years/21 months and 3.4 years/17 months, respectively. The median age of onset of uveitis after being diagnosed with arthritis was in the present study 1.7 years, which is in accordance with Papadopoulou et $\mathrm{al}^{9}$ presenting 12 months and Cassidy et $\mathrm{al}^{29}$ reporting that uveitis can occur years after JIA onset. A recent Nordic-population-based 

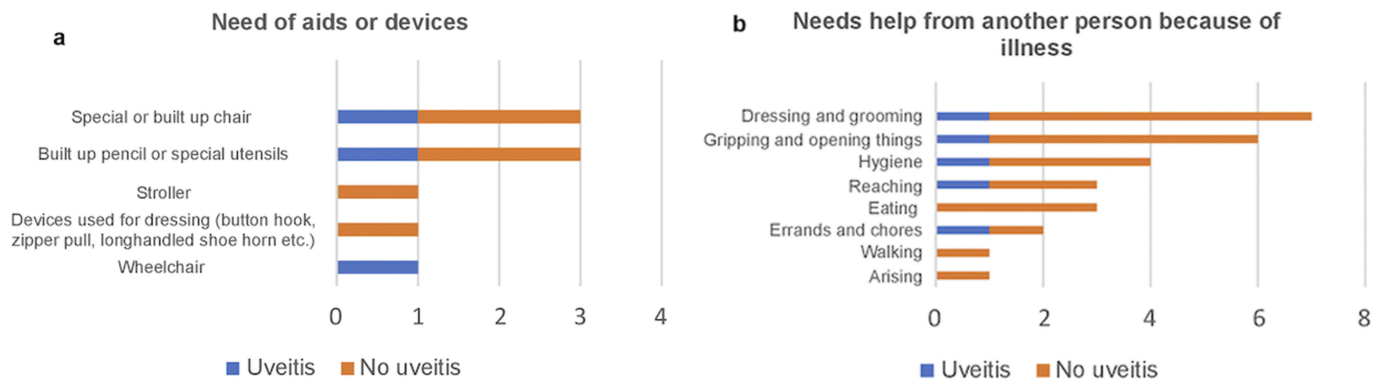

Figure I Number of children with juvenile idiopathic arthritis (IIA) needing special aids or devices documented by Child Health Assessment Questionnaire (CHAQ) (A) and number of children with JIA needing help from another person because of illness $(\mathbf{B})$.

Table 5 Comparison Of Effects Of Youngsters' Eyesight On Quality Of Life Questionnaire (EYE-Q) And Child Health Assessment Questionnaire (CHAQ) In Children With Juvenile Idiopathic Arthritis Having Visual Acuity $\leq$ or $>0.7$ Decimal (0.2 Logarithm Of The Minimum Angle Of Resolution)

\begin{tabular}{|c|c|c|c|c|}
\hline $\begin{array}{l}\text { Questionnaires On VR And HR } \\
\text { QoL }\end{array}$ & $\begin{array}{l}\text { JIA Children, } n= \\
40 *\end{array}$ & $\begin{array}{l}\text { VA Best Eye } \leq 0.7 \text { Decimal } \\
(0.2 \text { LogMAR), } n=5\end{array}$ & $\begin{array}{l}\text { VA Best Eye }>0.7 \text { Decimal } \\
(0.2 \text { LogMAR }), n=35^{*}\end{array}$ & P-Value \\
\hline $\begin{array}{l}\text { EYE-Q }(0-4)^{\mathrm{a}} \text { Median outcome scores } \\
(\text { range)** }\end{array}$ & $0.0(0.0-0.56)$ & $0.0(0.0-0.56) n=5$ & $0(0.0-0.11)=35$ & 0.013 \\
\hline $\begin{array}{l}\text { CHAQ }(0-3)^{\mathrm{a}} \text { disability index } \\
\text { Median outcome scores (range)** }\end{array}$ & $\begin{array}{l}0.0(0.0-1.32) \\
\mathrm{n}=40\end{array}$ & $0.143(0.0-1.32 I) n=5$ & $0.0(0.0-1.318) n=35$ & 0.066 \\
\hline CHAQ $(0-3)^{\mathrm{a}}$ self report $\geq 8 \mathrm{yrs}$ & $\begin{array}{l}0.0(0.0-0.517) \\
n=15\end{array}$ & & $0.0(0.0-0.517) n=15$ & \\
\hline $\begin{array}{l}\text { CHAQ }(0-3)^{\mathrm{a}} \text { parent report } \\
<8 \text { yrs }\end{array}$ & $\begin{array}{l}0.033(0.0-\mid .321) \\
\mathrm{n}=25\end{array}$ & $0.143(0.0-|.32|) n=5$ & $0.0(0.0-1.318) n=20$ & 0.21 \\
\hline \multicolumn{5}{|l|}{ CHAQ VAS Median (range) } \\
\hline Pain $(0-10)^{\mathrm{a}}$ & $\begin{array}{l}0.0(0.0-4.700) \\
n=40\end{array}$ & $\begin{array}{l}0.40(0.0-2.200) \\
n=5\end{array}$ & $\begin{array}{l}0.0(0.0-4.700) \\
n=35\end{array}$ & 0.63 \\
\hline $\begin{array}{l}\text { Pain }(0-10)^{\mathrm{a}} \text { self report } \\
\geq 8 \mathrm{yrs}\end{array}$ & $\begin{array}{l}0.0(0.0-4.200) \\
n=15\end{array}$ & & $\begin{array}{l}0.0(0.0-4.200) \\
n=15\end{array}$ & \\
\hline $\begin{array}{l}\text { Pain }(0-10)^{\mathrm{a}} \text { parent report } \\
<8 \text { yrs }\end{array}$ & $\begin{array}{l}0.20(0.0-4.700) \\
n=25\end{array}$ & $\begin{array}{l}0.40(0.0-2.200) \\
n=5\end{array}$ & $\begin{array}{l}0.10(0.0-4.700) \\
n=20\end{array}$ & 1.00 \\
\hline Overall well-being $(0-10)^{\mathrm{a}}$ & $\begin{array}{l}0.0(0.0-2.500) \\
\mathrm{n}=15\end{array}$ & $\begin{array}{l}1.70(0.0-3.80) \\
\mathrm{n}=5\end{array}$ & $\begin{array}{l}0.0(0.0-6.400) \\
\mathrm{n}=35\end{array}$ & 0.12 \\
\hline $\begin{array}{l}\text { Overall well-being }(0-10)^{\mathrm{a}} \text { self } \\
\text { report } \geq 8 \mathrm{yrs}\end{array}$ & $\begin{array}{l}0.0(0.0-2.500) \\
n=15\end{array}$ & & $\begin{array}{l}0.0(0.0-2.500) \\
n=15\end{array}$ & \\
\hline $\begin{array}{l}\text { Overall well-being }(0-10)^{\mathrm{a}} \text { parent } \\
\text { report }<8 \mathrm{yrs}\end{array}$ & $\begin{array}{l}0.90(0.0-6.40) \\
\mathrm{n}=25\end{array}$ & $\begin{array}{l}\mathrm{I} .70(0.0-3.80) \\
\mathrm{n}=5\end{array}$ & $\begin{array}{l}0.75(0.0-6.40) \\
n=20\end{array}$ & 0.39 \\
\hline
\end{tabular}

Notes: *Where numbers differ from the total number of children in the group, they are given separately for each category. **Median (range) is calculated on the mean of the scores for CHAQ disability index - parent and self-reports. ${ }^{2} H$ igher scores indicate worse quality of life.

Abbreviations: CHAQ, Childhood Health Assessment Questionnaire; EYE-Q, Effects of Youngsters' Eyesight on Quality of Life Questionnaire; HR, health-related; JIA, juvenile idiopathic arthritis; LogMAR, logarithm of the minimum angle of resolution; $n$, number of children; OoL, quality of life; VA, visual acuity; VAS, visual analogue scale; VR, visual-related.

cohort study of 435 JIA children reported that uveitis occurred in $20.5 \%$ of these children, whereas in $53.9 \%$, uveitis developed within the first year after the onset of arthritis. ${ }^{10}$
According to other studies, uveitis is more common in the OA subtype, whereas the extended OA subtype is thought to have the highest prevalence of uveitis $(25 \%){ }^{28,30}$ In our 

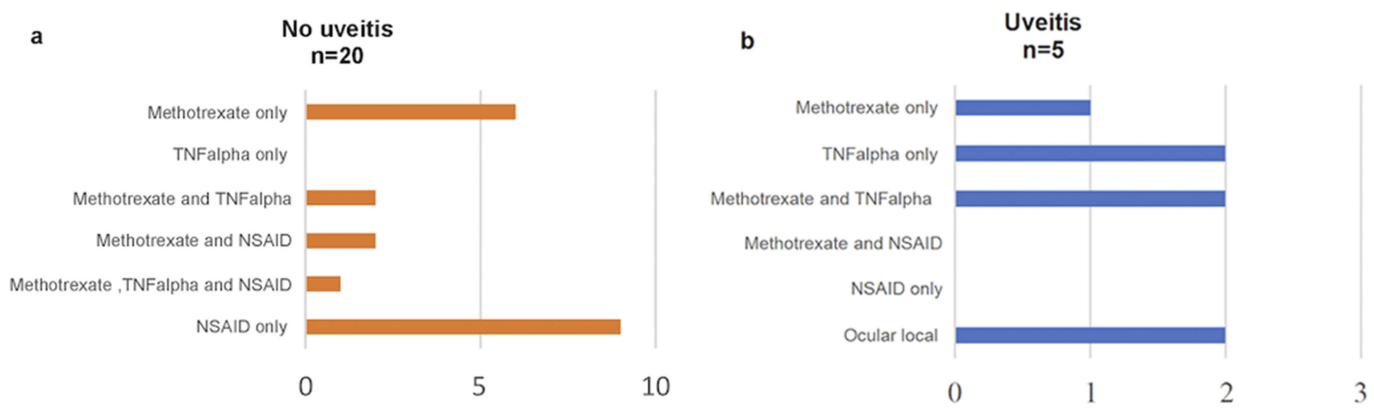

Figure 2 Medical treatment in 40 children without (A) and with (B) juvenile idiopathic arthritis (JIA)-associated uveitis at the time of assessment.

study, OA persistent was most common (57\%), which is in accordance with Papadopoulou et $\mathrm{al}^{9}$ reporting $50 \%$ of persistent OA subtype among the observed uveitis population.

Fledelius et $\mathrm{al}^{31}$ found, in a long-term follow-up, that $40 \%$ of 65 patients with juvenile chronic arthritis were myopic, and the mean refraction in these patients was significantly more towards myopia than that of a control group. A possible explanation, according to them, is weakness of scleral connective tissue in the early active phases of eye growth due to chronic inflammation. However, it is unclear whether the patients in the previous mentioned study have/have had uveitis. Notably, $40 \%$ of the children in our study was myopic, of which four of these were children with JIA-U.

Angeles-Han and colleagues found, when comparing EYE-Q with logMAR VA in the best eye/unaffected eye, moderate correlations between child and parent EYE-Q scores. ${ }^{18}$ We found a week correlation between BCVA LogMAR best eye and EYE-Q. However, worse EYE-Q scores were not necessarily associated with having uveitis; in fact, there was no sign of uveitis in two patients with the highest scores in EYE-Q. These patients may have/had other manifestations affecting their VR-QoL of yet unknown cause other than age. In several patients with the lowest scores possible in both CHAQ and EYE-Q, there was no need of medication. We also noted that the parent reports regarding need of aids/devices or need of assistance differed from the self-reports; the children older than 8 years of age did not need any of these.

The largest limitation of this study is the relatively small number of children with JIA and especially children with JIA-U which limits meaningful statistical analysis regarding EYE-Q and health-related OoL; however, our main focus was on the entire group and not only on those children with JIA-associated uveitis, especially when measuring with QoL in general. Most of the epidemiological data found in our study are in accordance with previous studies, despite our small study population. Other studies such as Singh et $\mathrm{al}^{21}$ have found a strong correlation between the parents' and children's responses when comparing the disability index of CHAQ. In our study, we found a difference in the responses of CHAQ well-being between the self-reports and parent reports, which indicates that the parents of 25 patients younger than 8 years experienced lower QoL compared to the older children, but for better comparable analysis we would like to have the questionnaires completed by the children of the 25 parents as well. However, we should consider whether parents can serve as reliable proxy reporters of their child's capabilities. According to Eiser et al, ${ }^{32}$ relying on either the child's self-report or the parent's proxy report alone will not give a complete picture in the clinical setting; parents' reports of their children's health may be influenced by their own well-being, their involvement in treatment and their responsibility for the child's daily care as well as them having information of diagnosis, prognosis, etc. However, regardless of the reason for the differences between the self-reports and parents-reports, it is important to be aware of these differences as they may contribute to a great clinical significance.

In conclusion, children with PA JIA subtype in our study had the highest scores of physical function assessment, which indicates worst QoL. Worse VA is indeed in accordance with worse VR function. Both the CHAQ and EYE-Q instruments scored low in general, which we believe is due to effective management of the arthritis disease as well as good screening programmes, strong collaboration between the ophthalmic and the paediatric clinics.

\section{Acknowledgments}

The authors would like to thank all the children and their families for participating in the study, and Anders Pehrsson, Senior Biostatistician of Statistiska Konsultgruppen, Gothenburg, for the statistical analyses. This work was 
supported by the Gothenburg Medical Society; the Aina Wallström and Mary-Ann Sjöblom Foundation for Medical Research; and the Wilhelm and Martina Lundgren Science Foundation.

\section{Disclosure}

The authors report no conflicts of interest in this work.

\section{References}

1. Ravelli A, Martini A. Juvenile idiopathic arthritis. Lancet. 2007;396 (9563):767-778. doi:10.1016/S0140-6736(07)60363-8

2. Angeles-Han ST, Griffin KW, Lehman TJ, et al. The importance of visual function in the quality of life of children with uveitis. $J$ Aapos. 2010;14(2):163-168. doi:10.1016/j.jaapos.2009.12.160

3. Thierry S, Fautrel B, Lemelle I, Guillemin F. Prevalence and incidence of juvenile idiopathic arthritis: a systemic review. Joint Bone Spine. 2014;81(2):112-117. doi:10.1016/j.jbspin.2013.09.003

4. Giancane G, Consolaro A, Lanni S, Davi S, Schiappapietra B, Ravelli A. Juvenile idiopathic arthritis: diagnosis and treatment. Rheumatol Ther. 2016;3(2):187-207. doi:10.1007/s40744-016-0040-4

5. Petty RE, Southwood TR, Manners P, et al. International League of Associations for Rheumatology classification of juvenile idiopathic arthritis: second revision, Edmonton, 2001. J Rheumatol. 2004;31(2):390-392.

6. Petty R, Southwood T, Baum J, et al. Revision of the proposed classification criteria for juvenile idiopathic arthritis: Durban 1997. J Rheumatol. 1998;25:1991-1994.

7. Heiligenhaus A, Niewerth M, Ganser G, Heinz C, Minden K. German Uveitis in Childhood Study Group. Prevalence and complications of uveitis in juvenile idiopathic arthritis in a population-based nation-wide study in Germany: suggested modification of the current screening guidelines. Rheumatology. 2007;46(6):1015-1019. doi:10.1093/rheumatology/kem045

8. Tappeiner C, Schenck S, Niewerth M, Heiligenhaus A, Minden K, Klotsche J. Impact of antiinflammatory treatment on the onset of uveitis in juvenile idiopathic arthritis: longitudinal analysis from a nationwide pediatric rheumatology database. Arthritis Care Res. 2016;68(1):46-54. doi:10.1002/acr.22649

9. Papadopoulou M, Zetterberg M, Oskarsdottir S, Andersson Grönlund M. Assessment of the outcome of ophthalmological screening for uveitis in a cohort of Swedish children with juvenile idiopathic arthritis. Acta Ophthalmol. 2017;95(7):741-747. doi:10.1111/aos.13273

10. Nordal E, Rypdal V, Christoffersen T, et al. Incidence and predictors of uveitis in juvenile idiopathic arthritis in a Nordic long-term cohort study. Pediatr Rheumatol Online J. 2017;15(1):66. doi:10.1186/ s12969-017-0195-8

11. Edelsten C, Reddy MA, Stanford MR, Graham EM. Visual loss associated with pediatric uveitis in English primary and referral centers. Am J Ophthalmol. 2003;135(5):676-680. doi:10.1016/ S0002-9394(02)02148-7

12. Rk S, Av L, Bm F, Rm L, Schneider R, Ed S. Risk factors for development of uveitis differ between girls and boys with juvenile idiopathic arthritis. Arthritis Rheum. 2010;62(6):1824-1828.

13. Asproudis I, Felekis T, Tsanou E, et al. Juvenile idiopathic arthritisassociated uveitis: data from a region in western Greece. Clin Ophthalmol. 2010;4:343-347.

14. Heiligenhaus A, Foeldvari I, Edelsten C, et al. Proposed outcome measures for prospective clinical trials in juvenile idiopathic arthritisassociated uveitis: a consensus effort from the Multinational Interdisciplinary Working Group for Uveitis in Childhood. Arthritis Care Res. 2012;64(9):1365-1372. doi:10.1002/acr.21674
15. Tappeiner C, Klotsche J, Sengler C, et al. Risk factors and biomarkers for the occurrence of uveitis in juvenile idiopathic arthritis. Data from the Inception Cohort of Newly Diagnosed Patients with Juvenile Idiopathic Arthritis Study. Arthritis Rheumatol. 2018;70 (10):1685-1694. doi:10.1002/art.40544

16. Zierhut M, Deuter C, Murray P. Classification of uveitis - current guidelines. 2011. doi:10.17925/EOR.2007.00.00.77

17. Moutakis K, Stigmar G, Hall-Linberg J. Using the KM visual acuity chart for more reliable evaluation of amblyopia compared to the HVOT method. Acta Ophthalmol Scand. 2004;82(5):547-551. doi:10.1111/j.1600-0420.2004.00307.x

18. Angeles-Han ST, Steven Y, McCracken C, et al. Measuring visual outcomes in children with uveitis using the "Effects of Youngsters Eyesight on Quality of Life" questionnaire. Arthritis Care Res. 2015;67(11):1513-1520. doi:10.1002/acr.22627

19. Angeles-Han ST, Griffin KW, Harrison MJ, et al. Development of a vision-related quality of life instrument for children ages 8-18 years for use in juvenile idiopathic arthritis-associated uveitis. Arthritis Care Res. 2011;63(9):1254-1261. doi:10.1002/acr.20524

20. Angeles-Han ST, McCracken C, Yeh S, et al. Characteristics of a cohort of children with juvenile idiopathic arthritis and JIA-associated uveitis. Pediatr Rheumatol Online J. 2015. doi:10.1186/ s12969-015-0018-8

21. Singh G, Athreya BH, Fries JF, Goldsmith DP. Measurement of health status in children with juvenile rheumatoid arthritis. Arthritis Rheum. 1994;37:1761-1769. doi:10.1002/art.1780370414

22. Pouchot J, Ecosse E, Coste J, Guillemin F. Validity of the childhood health assessment questionnaire is independent of age in juvenile idiopathic arthritis. Arthritis Rheum. 2004;51(4):519-526. doi:10.1002/art.20683

23. Gueddari S, Amine B, Rostom S, et al. Physical activity, functional ability, and disease activity in children and adolescents with juvenile idiopathic arthritis. Clin Rheumatol. 2014;33:1289-1294. doi:10.1007/s10067-0142576-4

24. Lelieveld OTHM, Armbrust W, van Leeuwen MA, et al. Physical activity in adolescents with juvenile idiopathic arthritis. Arthritis Rheumatol. 2008;59(10):1379-1384. doi:10.1002/art.24102

25. Grönlund MA, Andersson S, Aring E, Hård AL, Hellström A. Ophthalmological findings in a sample of Swedish children aged 415 years. Acta Ophthalmol Scand. 2006;84(2):169-176. doi:10.1111/ j.1600-0420.2005.00615.x

26. Pocock SJ, Simon R. Sequential treatment assignment with balancing for prognostic factors in the controlled clinical trial. Biometrics. 1975;31(1):103-115. doi:10.2307/2529712

27. Miyamae T, Nemoto A, Imagawa T, et al. Cross-cultural adaptation and validation of the Japanese version of the Childhood Health Assessment Questionnaire (CHAQ). Mod Rheumatol. 2008;18:336343. doi:10.3109/s10165-008-0047-y

28. Kotaniemi K, Kautiainen H, Karma AA, Aho KK. Occurrence of uveitis in recently diagnosed juvenile chronic arthritis: a prospective study. Ophthalmology. 2001;108(11):2071-2075. doi:10.1016/S01616420(01)00773-4

29. Cassidy JT, Sullivan DB, Petty RE. Clinical patterns of chronic iridocyclitis in children with juvenile rheumatoid arthritis. Arthritis Rheum. 1977;20(2):224-227.

30. Sim KT, Venning HE, Barrett S, Gregson RM, Amoaku W. Extended oligoarthritis and other risk factors for developing JIA-associated uveitis under ILAR classification and its implication for current screening guideline. Ocul Immunol Inflamm. 2006;14(6):353-357. doi:10.1080/09273940600977233

31. Fledelius H, Zak M, Pedersen FK. Refraction in juvenile chronic arthritis: a long-term follow-up study, with emphasis on myopia. Acta Ophthalmol Scand. 2001;79(3):237-239. doi:10.1034/j.1600-0420.2001.790305.x

32. Eiser C, Varni JW. Health-related quality of life and symptom reporting: similarities and differences between children and their parents. Eur $J$ Pediatr. 2013;172(10):1299-1304. doi:10.1007/s00431-012-1889-z 


\section{Publish your work in this journal}

Clinical Ophthalmology is an international, peer-reviewed journal covering all subspecialties within ophthalmology. Key topics include: Optometry; Visual science; Pharmacology and drug therapy in eye diseases; Basic Sciences; Primary and Secondary eye care; Patient Safety and Quality of Care Improvements. This journal is indexed on PubMed
Central and CAS, and is the official journal of The Society of Clinical Ophthalmology (SCO). The manuscript management system is completely online and includes a very quick and fair peer-review system, which is all easy to use. Visit http://www.dovepress.com/ testimonials.php to read real quotes from published authors. 